\title{
Aerosol climatology and planetary boundary influence at the Jungfraujoch analyzed by synoptic weather types
}

\author{
M. Collaud Coen ${ }^{1}$, E. Weingartner ${ }^{2}$, M. Furger ${ }^{2}$, S. Nyeki ${ }^{3}$, A. S. H. Prévôt ${ }^{2}$, M. Steinbacher ${ }^{4}$, and U. Baltensperger ${ }^{2}$ \\ ${ }^{1}$ MeteoSwiss, Aerological Station, Les Invuardes, 1530 Payerne, Switzerland \\ ${ }^{2}$ Laboratory of Atmospheric Chemistry, Paul Scherrer Institut, 5232 Villigen PSI, Switzerland \\ ${ }^{3}$ Physikalisch-Meteorologisches Observatorium Davos and Word Radiation Center (PMOD/WRC), \\ 7260 Davos Dorf, Switzerland \\ ${ }^{4}$ Empa, Swiss Federal Laboratories for Materials Science and Technology, 8600 Dübendorf, Switzerland
}

Received: 3 December 2010 - Published in Atmos. Chem. Phys. Discuss.: 14 January 2011

Revised: 31 May 2011 - Accepted: 7 June 2011 - Published: 23 June 2011

\begin{abstract}
Fourteen years of meteorological parameters, aerosol variables (absorption and scattering coefficients, aerosol number concentration) and trace gases $\left(\mathrm{CO}, \mathrm{NO}_{\mathrm{x}}\right.$, $\mathrm{SO}_{2}$ ) measured at the Jungfraujoch (JFJ, $3580 \mathrm{~m}$ a.s.l.) have been analyzed as a function of different synoptic weather types. The Schüepp synoptic weather type of the Alps (SYNALP) classification from the Alpine Weather Statistics (AWS) was used to define the synoptic meteorology over the whole Swiss region. The seasonal contribution of each synoptic weather type to the aerosol concentration was deduced from the aerosol annual cycles while the planetary boundary layer (PBL) influence was estimated by means of the diurnal cycles. Since aerosols are scavenged by precipitation, the diurnal cycle of the $\mathrm{CO}$ concentration was also used to identify polluted air masses. $\mathrm{SO}_{2}$ and $\mathrm{NO}_{\mathrm{x}}$ concentrations were used as precursor tracers for new particle formation and growth, respectively. The aerosol optical parameters and number concentration show elevated loadings during advective weather types during the December-March period and for the convective anticyclonic and convective indifferent weather types during the April-September period. This study confirms the consensus view that the JFJ is mainly influenced by the free troposphere during winter and by injection of air parcels from the PBL during summer. A more detailed picture is, however, drawn where the JFJ is completely influenced by free tropospheric air masses in winter during advective weather types and largely influenced by the
\end{abstract}

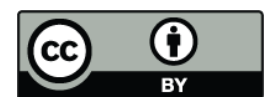

Correspondence to: M. Collaud Coen (martine.collaud@meteoswiss.ch)
PBL also during the night in summer during the subsidence weather type. Between these two extreme situations, the PBL influence at the JFJ depends on both the time of year and the synoptic weather type. The fraction of PBL air transported to the JFJ was estimated by the relative increase of the specific humidity and $\mathrm{CO}$.

\section{Introduction}

The Jungfraujoch (JFJ) Sphinx research station is situated at $3580 \mathrm{~m}$ a.s.l. in the middle of the Swiss Alps (Fig. 1). Since 1995 continuous aerosol and trace gas measurements have been performed at this site within the Global Atmosphere Watch (GAW) program of the World Meteorological Organization. Due to its high elevation, the JFJ research station allows investigation of the lower free troposphere (FT) over central Europe and the mixing of planetary boundary layer (PBL) and FT air masses. It is recognized as a station measuring FT air masses, even if the JFJ is partially influenced by the PBL. The annual cycle of all measured aerosol variables (absorption coefficient $b_{\text {abs }}$, scattering coefficients $b_{\text {scat }}$, aerosol number concentration $N$, aerosol surface area concentration, chemical composition, particle mass concentration, and radon decay product concentration), which attain a maximum in summer and a minimum in winter, can be attributed to the vertical transport of PBL air masses by thermally-driven convection occurring from late spring to late summer (Baltensperger et al., 1997; Nyeki et al., 1998a; Lugauer et al., 1998, 2000). Autumn is far less influenced by this dominant transport mode (Lugauer et al.,

Published by Copernicus Publications on behalf of the European Geosciences Union. 


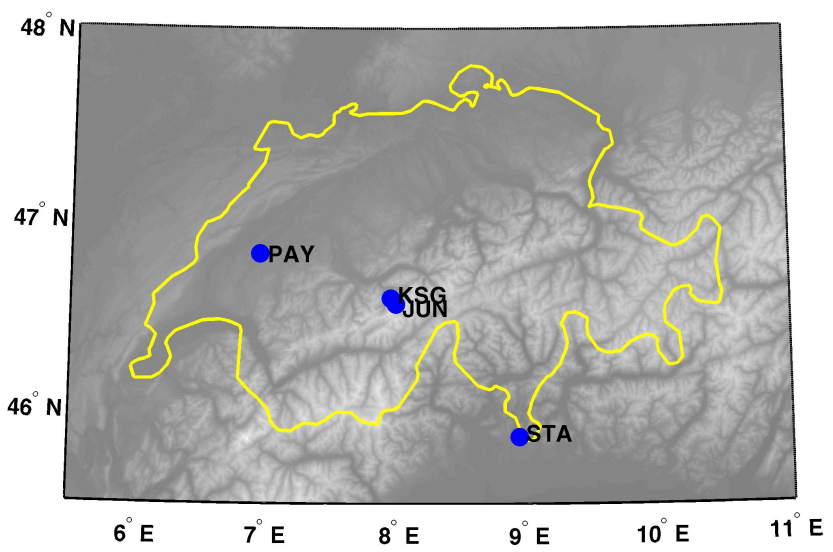

Fig. 1. Map of Switzerland with the four measuring sites of Payerne (PAY), Jungfraujoch (JFJ), Kleine Scheidegg (KSG) and Stabio (STA). The altitude is given by the grey color scheme.

1998, 2000). The regional extent of thermally-driven convection was studied during an airborne lidar campaign over the JFJ and the Swiss Alps. The gradual evolution of the PBL on a summer day in 1997 clearly showed that the PBL attained a near-uniform height of up to $4200 \mathrm{~m}$ a.s.l. by the early afternoon (Nyeki et al., 2000). A later in-situ and airborne study by Henne et al. (2004) reported that PBL air was efficiently injected into the altitude range from 2000 to $4000 \mathrm{~m}$ a.s.l. where it had a substantial influence on air mass chemistry (Henne et al., 2005a). These processes are important from May to September, especially in summer (Henne et al., 2005b), so that the transport mechanisms of air masses to the JFJ during the warmest months depend mainly on these PBL injections over the whole Alpine area rather than on the local, thermally induced upslope wind. The annual cycle was observed in one-year measurements of several insitu aerosol variables $\left(b_{\mathrm{abs}}, b_{\text {scat }}, N\right.$, etc.) (Nyeki et al., 1998a). Long-term trends were found to be positive and statistically significant in winter, when the FT influence at the JFJ is the greatest (Collaud Coen et al., 2007). The PBL influence does not modify the aerosol size distribution to any large extent, but mainly influences the concentration of accumulation mode particles (Weingartner et al., 1999; Nyeki et al., 1998b). Diurnal cycles are observed for all the measured aerosol variables during the warm months and are more pronounced in convective meteorological situations (Weingartner et al., 1999; Lugauer et al., 2000). Analyses of the aerosol surface area concentration, concentrations of radon decay products, and the total aerosol mass concentration as a function of the Alpine Weather Statistics (SYNALP) scheme show that synoptic-scale lifting processes occur occasionally in winter and more significantly in April. In addition, maximum values in aerosol variables are attained during anticyclonic conditions (Lugauer et al., 1998, 2000). It was also shown that transport of gaseous and aerosol species is similar during anticyclonic but different during cyclonic conditions.
Lugauer et al. (1998, 2000) analyzed long time series (9 years and 7 years) of the aerosol surface area concentration, aerosol-attached radon decay products and the mass concentration of Total Suspended Particles (TSP) as a function of SYNALP classification defined by Schüepp (1979). Nyeki et al. (1998) and Weingartner et al. (1999) presented one-year time series of aerosol parameters measured operationally in the GAW program. In this paper, climatologies (14-year data set, 1995-2008) of the optical aerosol parameters ( $\left.b_{\text {abs }}, b_{\text {scat }}\right)$ and particle number $N$ are presented. The contribution of the SYNALP synoptic weather types to the median aerosol seasonal cycle is determined. Correlations between the aerosol seasonal cycle and the local meteorological conditions are also evaluated. Since aerosols are one of the most sensitive parameters to the influence of the PBL (due to a strong vertical gradient), this paper also presents a study of the transport of air masses from the PBL to the JFJ analyzed by the diurnal cycles of $N, b_{\mathrm{abs}}, b_{\text {scat }}$ and the scattering Ångström exponent $\stackrel{\circ}{\text { scat }}_{\text {as a function of the year periods and synoptic }}$ weather types. The absorption coefficient is mostly determined by the black carbon concentration arising from combustion processes, and is hence more characteristic of polluted air masses. $N$ is the most sensitive parameter to the formation and subsequent growth of new particles (Weingartner et al., 1999), because the number concentration is governed by Aitken mode particles whereas $b_{\mathrm{abs}}$ is proportional to an equivalent mass of black carbon and $b_{\text {scat }}$ is sensitive to accumulation and coarse mode particles (Chamaillard et al., 2006). However, $N$ is also sensitive to primary pollution sources. The scattering coefficient is sensitive to both primary pollution and condensational growth of the particles and thus combines characteristics of both $b_{\text {abs }}$ and $N$. In combination with $\mathrm{SO}_{2}$ and $\mathrm{NO}_{\mathrm{x}}$ concentrations (which are precursors for aerosol number and mass concentration, respectively) and with meteorological parameters favorable for new particle formation, $N$ allows new particle formation events at the JFJ and on the Swiss plateau to be determined. In addition, as $\mathrm{CO}$ is not washed out by precipitation in contrast to aerosols, it can also be used as a tracer for polluted air masses during weather situations with precipitation. However, $\mathrm{CO}$ has a less pronounced vertical profile than other chemical species due to a longer atmospheric lifetime, resulting in higher background concentrations and less pronounced diurnal cycles (Zellweger et al., 2000). Finally, the mean export of PBL air to the JFJ will be quantified by the relative increase of $\mathrm{CO}$ and the specific humidity (remains constant during vertical motion in the absence of precipitation).

\section{Experiment}

\subsection{Measurement site}

The JFJ high alpine research station $\left(46^{\circ} 33^{\prime} \mathrm{N}, 7^{\circ} 59^{\prime} \mathrm{E}\right)$ is located on a mountain crest on the northern edge of the Swiss 
Alps. The saddle position of the JFJ, between the Jungfrau (4158 $\mathrm{m}$ a.s.1.) and the Mönch (4089 m a.s.l.) mountains, channels the local horizontal flow in a north-western or south-eastern direction. With north-westerly wind directions, air-masses from over the Swiss plateau are advected to the JFJ, while during south-easterly wind direction, air-masses come from the inner Alpine area and from South of the Alps. Contamination due to local sources is rare as electricity is supplied by a high-voltage connection from the valley. A local diesel generator is only in operation for short periods during power failures. Emissions due to tourist activities are usually negligible. All diurnal times mentioned in this study are given as local standard time LST (equal to UTC $+1 \mathrm{~h}$ ).

\subsection{Instrumentation and methods}

Ambient aerosol particles were sampled and measured at the old JFJ research station (3454 m a.s.l.) from 1995 to January 1998 and at the JFJ Sphinx research station (3580 m a.s.l.) thereafter with a new inlet. At both sites, the aerosol is first brought into the laboratory (mean temperature of $22( \pm 2)^{\circ} \mathrm{C}$ ), which lowers the relative humidity $(\mathrm{RH})$ to below $20 \%$. Therefore cloud droplets are evaporated at an early stage of the sampling process, so that only dried aerosols are measured. Calculations for the latter inlet set-up showed that cloud droplets with a diameter smaller than $40 \mu \mathrm{m}$ can be sampled at wind speeds of up to $20 \mathrm{~m} \mathrm{~s}^{-1}$ (Weingartner et al., 1999). No discontinuities induced by the altitude and inlet changes were detected in the aerosol data sets (Collaud Coen et al., 2007).

The aerosol light scattering and backscattering coefficients were measured at three wavelengths $(\lambda=450,550$ and $700 \mathrm{~nm}$ ) by an integrating nephelometer (IN, TSI 3563) and were corrected for the truncation error according to Anderson and Ogren (1998) and Nessler et al. (2005), which makes use of the scattering Ångström exponent $\stackrel{a}{s c a t}_{\text {sc }}$ to calculate the wavelength dependent correction factor. The value of $\stackrel{\circ}{\text { scat }}_{\text {sat }}$ was obtained by fitting $b_{\text {scat }}$ with a power-law dependence $b_{\text {scat }}=\beta_{\text {scat }} \cdot \lambda^{-\mathrm{a}_{\text {scat }}}$.

The aerosol light absorption coefficients were measured by two different aethalometers. A "white light" aethalometer (AE-10, Magee Scientific) with a broad spectral range from $500 \mathrm{~nm}$ to $1100 \mathrm{~nm}$ and a peak sensitivity in the near IR at about $840 \mathrm{~nm}$ (Weingartner et al., 2003) was used until March 2001. A 7-wavelength aethalometer (AE-31, Magee Scientific) with narrow band light sources in the wavelength range $370-950 \mathrm{~nm}$ was operated thereafter. The absorption coefficients for both aethalometers were calculated by the correction method described by Collaud Coen et al. (2010). The multiple scattering constant $C_{\text {ref }}=2.88$ was determined by comparing the absorption coefficients from a multi-angle absorption photometer and the multi-wavelength aethalometer and was applied to the AE-31. A slightly higher value for the AE-10, $C_{\text {ref }}=2.97$, was estimated by normalizing both datasets, and is anticipated since the AE-10 filter tapes differ from those of the AE-31. For analysis of the whole 19952008 period, the $\lambda=880 \mathrm{~nm}$ channel from the AE-31 was chosen as it is closest to the maximum light source intensity of the AE-10.

The aerosol number concentration was measured using a TSI 3025 condensation particle counter (CPC) before March 1997, and a TSI 3010 thereafter. Although both CPCs have slightly different lower aerosol diameter cut-offs, all data were considered since only the cycles and not the trends were studied in this paper.

All meteorological parameters, (temperature $T$, relative humidity $\mathrm{RH}$, global short wave radiation $W$ (from $\lambda=200 \mathrm{~nm}$ to $\lambda=3.6 \mu \mathrm{m}$ ), erythemally weighted ultra-violet radiation UV (from $\lambda=200 \mathrm{~nm}$ to $\lambda=340 \mathrm{~nm}$ ), and wind speed and direction) were measured by MeteoSwiss at the JFJ, Payerne $\left(46.82^{\circ} \mathrm{N}, 6.95^{\circ} \mathrm{E}, 491 \mathrm{~m}\right.$ a.s.l.) and Stabio $\left(45.85^{\circ} \mathrm{N}, 8.93^{\circ} \mathrm{E}, 353 \mathrm{~m}\right.$ a.s.l.) SwissMetNet stations (Fig. 1). Precipitation is not measured at the JFJ, but daily precipitation (from 5:40 a.m. to 5:40 a.m. the day after) is measured at the Kleine Scheidegg (2061 m a.s.l.) located at the foot of the Eiger mountain next to the Mönch and the JFJ.

Continuous trace gas measurements are performed at the JFJ Sphinx laboratory as part of the Swiss National Air Pollution Monitoring Network (NABEL). CO has been measured with cross flow modulated non-dispersive infrared absorption technology (NDIR, Horiba APMA-360; since June 2007, APMA-370). $\mathrm{NO}$ and $\mathrm{NO}_{\mathrm{x}}$ are determined with chemiluminescence detectors (Ecophysics CLD 770 AL ppt, and CLD89p since January 2007). $\mathrm{NO}_{\mathrm{x}}$ is analyzed as NO after photolytic conversion (Ecophysics PLC 760, and Ecophysics PLC 762 since 2000). $\mathrm{SO}_{2}$ was previously measured as 24-h bulk samples by wet chemical absorption of $\mathrm{SO}_{2}$ in a hydrogen peroxide solution and subsequent offline analysis with ion chromatography. Since January 2007, $\mathrm{SO}_{2}$ has been measured on-line with a UV fluorescence instrument (Thermo Electro Cooperation, Enviromental Instruments, TEI43C TL). The trace gas observations at Payerne used in this study (CO with a Horiba APMA-360; $\mathrm{SO}_{2}$ with a MonitorLabs 8850S, since June 2000, TEI43C TL) are also conducted within the NABEL network. All gaseous concentrations are given in ppbv.

Median values were calculated for the aerosol and gasphase variables that are neither normally nor lognormally distributed, while for normally distributed variables arithmetic mean values were computed. Confidence limits of the medians were calculated by a nonparametric method defined by an order statistic (i.e. rank observation) and using the cumulative binomial distribution (Gibbons and Coleman, 2001). A running 30-day average was also applied to the annual cycles. For the annual cycles of aerosol variables, precipitation and gaseous compounds, the contributions of each synoptic weather type to the averaged annual cycles were determined by weighting the measured parameters during the 
defined weather type by its frequency of occurrence:

$$
Y=\sum_{i=1}^{\text {nb_SYNALP }} Y_{\text {SYNALP }(i)}=\sum_{i=1}^{\text {nb_SYNALP }} \bar{y}_{\operatorname{SYNALP}(i)} \cdot \frac{m_{\operatorname{SYNALP}(i)}}{m_{\text {total }}}
$$

where $Y$ is the average annual value, with the summation performed over all weather types (nb_SYNALP). $\bar{y}_{\text {SYNALP }(i)}$ is the average value during the SYNALP $(i)$ weather type, $m_{\text {SYNALP }(i)}$ is the number of cases with $\operatorname{SYNALP}(i)$ weather type and $m_{\text {total }}$ is the total number of cases (=number of years). $Y_{\text {SYNALP }(i)}$ is the contribution of the $i^{\text {th }}$ SYNALP weather type and is represented with a different color in Figs. 3, 5 and 8.

\subsection{Alpine weather type classification}

The synoptic weather types classification system (SYNALP) (Schüepp, 1979; SMI, 1985) is a daily classification of synoptic weather situations based on the diurnal analysis of the pressure distribution at the surface and at $500 \mathrm{hPa}$ $(\sim 5.6 \mathrm{~km}$ a.s.1.). It is defined for a circular area (radius of $222 \mathrm{~km})$ centered $80 \mathrm{~km}$ east of the JFJ $\left(46^{\circ} 30^{\prime} \mathrm{N}, 9^{\circ} \mathrm{E}\right)$ and covering Switzerland and western Austria. The classification into 40 weather situations is determined by the combination of four key parameters at 12:00 UTC (Schüepp, 1979; Wanner et al., 1998):

1. speed of the surface wind derived from the surface pressure gradient,

2. direction and speed of the $500 \mathrm{hPa}$ wind,

3. height of the $500 \mathrm{hPa}$ surface over the central point of the system,

\section{4. baroclinicity.}

If these parameters cannot be unambiguously determined from the 12:00 UTC surface map, the corresponding $850 \mathrm{hPa}$ heights or the 15:00 UTC or the 09:00 UTC surface map are additionally taken in account (SMI, 1985). The determined 40 weather situations can be grouped into three basic (convective, advective and mixed) and eight extended weather types (Table 1).

The convective types describe weather situations where the vertical motion predominantly influences the weather, either as a single effect or in connection with the effects of horizontal motion. The three convective weather types differ by the sign of the synoptic scale vertical motion (Lugauer et al., 1998). Divergence at low altitude caused by subsidence is predominant for the anticyclonic type CA, resulting in adiabatic warming and cloud dissipation. This synoptic subsidence does not induce upward vertical transport of PBL air masses on a large scale; however, the temperature and the global radiation (low cloud coverage) are a maximum during subsidence, leading to PBL growth and thermally induced injections of PBL air that can reach the altitude of the JFJ.
Ascent of air caused by convergence at low altitude is predominant for the cyclonic type $\mathrm{CC}$, resulting in adiabatic cooling and cloud formation with subsequent precipitation. The convective indifferent weather type CI is characterized by a flat pressure distribution and therefore alternating smallscale up- and downdrafts depending on the effects of the terrain (Schüepp and Schirmer, 1977). The difference in the synoptic scale vertical motion of weather types CA and CC results in differences in the thermodynamic variables that are considerably more pronounced than between the four advective weather types.

The advective types include weather situations where the horizontal motion of the atmosphere is predominant, so that in flat terrain the vertical wind components are unimportant. However, the orography of the Alps adds vertical components to this air flow resulting in well-marked upslope and lee phenomena (Schüepp and Schirmer, 1977; Henne et al., 2004) such as Foehn. Eight wind sectors of $45^{\circ}$ are distinguished depending on the wind direction at the $500 \mathrm{hPa}$ level over the central Alpine area. The number of sectors within each advective type is different (Table 1). The AW type comprises only one wind sector and is characterized by advection of maritime air masses from the Atlantic. The AN type comprises two wind sectors and occurs when the Alps are influenced by cold polar air masses after a cyclone has passed to the North of Switzerland (Schüepp, 1979). The AE type comprises three wind sectors and represents situations when the usual zonal circulation is blocked. The AS type comprises two wind sectors and induces most precipitation on the southern side of the Alps. Vertical motion due to the Alpine orography during advective types is often associated with cloud formation and precipitation on the upwind side. The aerosol concentration at high Alpine sites is therefore not only determined by the different origin of air masses but also by modifications arising from the forced vertical motion. This is reflected in the small differences in aerosol concentration for each advective type associated with high differences in aerosol concentration between the JFJ and Colle Gnifetti (4452 $\mathrm{m}$ a.s.1., approximately $75 \mathrm{~km}$ southwest of the JFJ) (Lugauer et al., 1998). The diurnal cycles are partly used in this study to determine the PBL influence at the JFJ. Synoptic and topographic lifting during advective situations does not depend on the time of the day, so that the absence of a diurnal cycle does not imply that there is no PBL influence. The values of aerosol variables allow the PBL influence in these cases to be estimated.

The mixed type $\mathrm{M}$ describes weather situations where both the horizontal and the vertical wind components are significant, and occurs when an active cyclone or a front is present in the surface chart.

The weather types AW, AN, and AE show similar annual and diurnal cycles for aerosol and some meteorological parameters and hence these three types were grouped $(\mathrm{AW}+\mathrm{N}+\mathrm{E})$ in the analyses and the figures for clarity. 
Table 1. The SYNALP synoptic weather types described by 3 basic types, 8 extended types, and by the dominant synoptic scale motion.

\begin{tabular}{lccc}
\hline Basic weather type & Extended type & Abbreviation & Synoptic motion \\
\hline Convective & Anticyclonic & CA & Subsidence \\
& Indifferent & CI & Small-scale circulations \\
& Cyclonic & CC & Lifting \\
Advective & West & AW & W at $500 \mathrm{hPa}$ \\
& North & AN & NW-N at $500 \mathrm{hPa}$ \\
& East & AE & NE-SE at $500 \mathrm{hPa}$ \\
Mixed & South & AS & S-SW at $500 \mathrm{hPa}$ \\
& & M & Active cyclone or jet flow \\
\hline
\end{tabular}

Table 2. Yearly frequency distribution in percent of SYNALP weather types for 1945-1994 (Wanner et al., 1998), 1988-1996 (Lugauer et al., 1998) and 1995-2008. For the 1995-2008 period (this work) the spread in data corresponding to two standard deviations is given.

\begin{tabular}{cccccc}
\hline & CA & CI & CC & A & M \\
\hline $1945-1994$ & 16.5 & 27.4 & 7.4 & 42.6 & 6.2 \\
$1988-1996$ & 23.0 & 31.3 & 6.4 & 35.4 & 3.9 \\
$1995-2008$ & $20.9 \pm 9.2$ & $30.3 \pm 8.0$ & $6.7 \pm 4.6$ & $35.7 \pm 6.0$ & $6.4 \pm 3.8$ \\
\hline
\end{tabular}

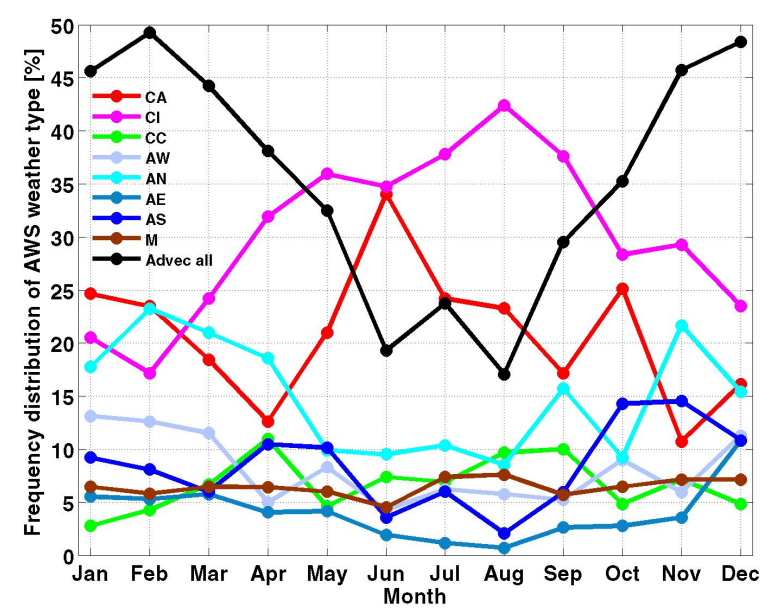

Fig. 2. Monthly frequency distribution of SYNALP weather types for the 1995-2008 period.

\section{Results}

\subsection{Occurrence and annual cycle of SYNALP synoptic weather types}

The mean frequency distribution of SYNALP weather types during the 1995-2008 period is presented in Fig. 2 for each month. Advective weather types are seen to predominate during winter and convective weather types during the rest of the year. Similar annual frequency distributions were calculated by Wanner for the 1945-1994 period (Wanner et al., 1998; Stefanicki et al., 1998) and by Lugauer for the 19881996 period (Lugauer et al., 1998). The mixed weather type frequency is fairly constant during the year, always ranging between $5 \%$ and $8 \%$. Within the convective weather types, CI predominates almost during the whole year with a clear annual cycle that reaches a maximum in summer $(\sim 40 \%)$ and a minimum in winter $(\sim 20 \%)$. The CA type also occurs often (10-35\%), however, without a very clear annual cycle. The $\mathrm{CC}$ type occurs more frequently during spring and autumn, but its frequency never exceeds $11 \%$. Advective weather types have an inverse annual cycle to the CI type, with a minimum occurrence during summer $(\sim 20 \%)$ and a maximum occurrence during winter (45-50\%) when vertical motion is suppressed by enhanced stability of the atmosphere (Schüepp and Schirmer, 1977). All the extended advective weather types show similar annual cycles with AN being the most frequent wind sector and $\mathrm{AE}$ the least frequent.

Schwarb (1996), as well as Stefanicki et al. (1998) and Wanner et al. (1998) showed that there has been an increase in frequency of convective weather situations and a concurrent decrease in frequency of advective weather situations since the early 1970s. These are strongly correlated with the North Atlantic Oscillation (NAO) index and are due to higher surface air pressure and lower horizontal pressure gradients. Table 2 gives the frequency distribution of SYNALP weather types for the 1945-1994 (Wanner et al., 1998), the 19881996 (Lugauer et al., 1998) and the 1995-2008 periods. The two more recent periods clearly have a greater occurrence of CA and CI weather type, a slightly lower occurrence of lifting $\mathrm{CC}$ and a substantially lower frequency of all advective weather types than the former period. The mixed weather type M occurred 6\% of the time for both the 1945-1994 and the 1995-2008 periods, whereas the occurrence is lower for the 1988-1996 period. 
Table 3. Diurnal cycle amplitude (maximum/minimum) for the temperature and the relative humidity as a function of the season and the synoptic weather type.

\begin{tabular}{lcccccccccc}
\hline WL & \multicolumn{3}{c}{$T_{\max } / T_{\min }$} & \multicolumn{5}{c}{$\mathrm{RH}_{\max } / \mathrm{RH}_{\min }$} \\
\hline season & Nov-Jan & Feb-Mar & Apr-May & Jun-Aug & Sep-Oct & Nov-Jan & Feb-Mar & Apr-May & Jun-Aug & Sep-Oct \\
CA & 1.10 & 1.13 & 1.26 & 1.47 & 1.26 & 1.06 & 1.11 & 1.42 & 1.36 & 1.21 \\
CI & 1.06 & 1.09 & 1.19 & 1.28 & 1.16 & 1.03 & 1.09 & 1.16 & 1.22 & 1.14 \\
CC & 1.06 & 1.05 & 1.11 & 1.16 & 1.09 & 1.08 & 1.12 & 1.11 & 1.14 & 1.09 \\
A W+N+E & 1.08 & 1.09 & 1.14 & 1.27 & 1.14 & 1.16 & 1.30 & 1.11 & 1.15 & 1.16 \\
AS & 1.06 & 1.04 & 1.13 & 1.19 & 1.08 & 1.12 & 1.13 & 1.13 & 1.45 & 1.10 \\
M & 1.03 & 1.04 & 1.09 & 1.11 & 1.07 & 1.08 & 1.06 & 1.15 & 1.23 & 1.11 \\
\hline
\end{tabular}

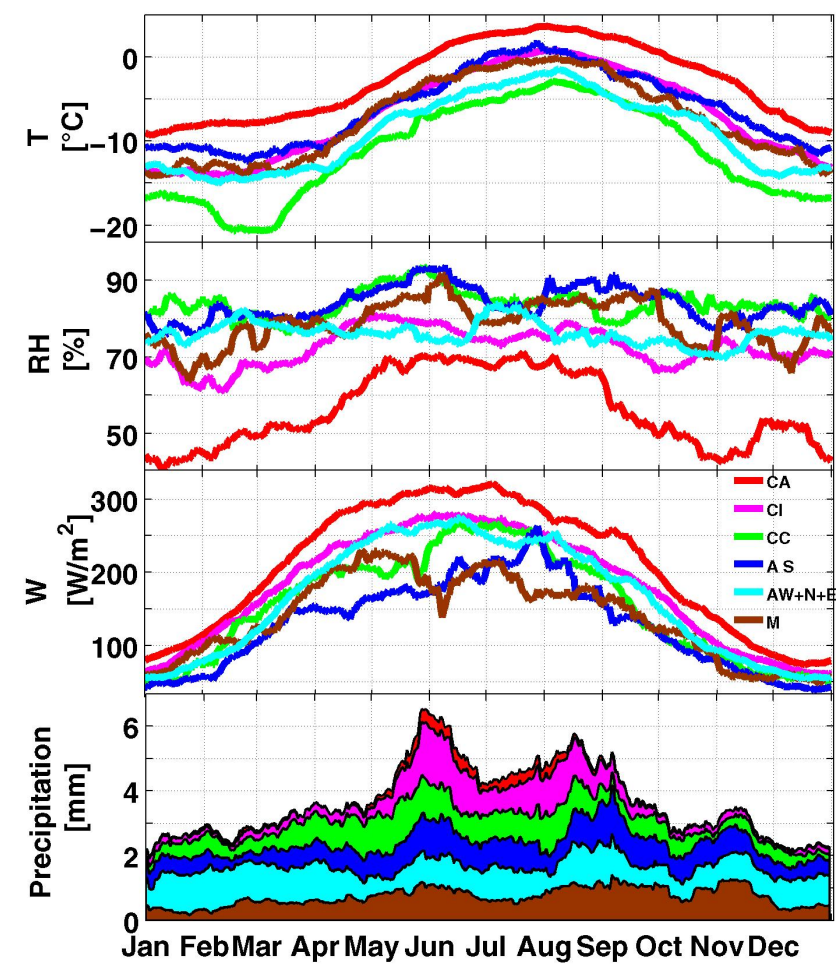

Fig. 3. Mean 1995-2008 annual cycles of the temperature $T$, the $\mathrm{RH}$, the global short wave radiation $W$ at the JFJ and the precipitation at the Kleine Scheidegg as a function of SYNALP weather types.

A least-mean square fit allowing trends of monthly averages to be determined (Weatherhead et al., 1998, 2000) was used to determine possible trends in the frequency of occurrence of the synoptic weather types during the analyzed 14years. Only one statistically significant trend at $90 \%$ confidence level was detected: $\mathrm{CC}$ weather type has a negative trend of $-4 \% / y e a r$. Due to the very low frequency of occurrence of this weather type, this corresponds to $-2 \mathrm{~h} /$ year or -1 day/12 years. This very small trend cannot induce significant change in the PBL influence at the JFJ.

\subsection{Mean annual and diurnal cycles of meteorological parameters}

The mean 14-year annual cycles of $T, \mathrm{RH}, W$ at the JFJ and precipitation (at the Kleine Scheidegg) are presented in Fig. 3 and the corresponding mean diurnal cycles for the AprilMay period in Fig. 4. The UV cycles are similar to the $W$ cycles and will therefore not be presented here. Diurnal cycles of precipitation are not shown either since only daily values are available at the Kleine Scheidegg.

During the CA weather type associated with subsidence, $T, W$ and UV are higher and the $\mathrm{RH}$ and the precipitation lower than for all other weather types during the whole year. Contrary to all other weather types, the $\mathrm{RH}$ annual cycle is well defined during CA situations, with a minimum in January $(45 \%)$ and a broad maximum in the May-August period. All these features can be explained by the adiabatic warming and cloud dissipation induced by CA situations. CA situations also generally present the largest $T, W$ and RH diurnal cycles (Fig. 4, Table 3).

During the CC weather type associated with lifting, $T$ is lower than for all other weather types. A marked minimum in $T$ is found in February-March and can be explained by a greater occurrence of CC with northerly upper wind (52\%) than during the rest of the year $(30 \%)$, leading to a large influence of Arctic air masses. A climatology of the Swiss Alps (Urfer, 1979) describes February as the coldest month for regions higher than $1500 \mathrm{~m}$ a.s.l. as well as the month with a large number of extreme cases leading to a minimum in $T$ far lower than the mean $T$ for the whole northern region of the Alps. During the whole year, CC situations are also characterized by high $\mathrm{RH}$ and precipitation and intermediate $W$ and UV values.

The CI weather type leads to $T$ and $\mathrm{RH}$ values between those of $\mathrm{CA}$ and $\mathrm{CC}$, but to lower cloud coverage than for $\mathrm{CC}$ (as seen by $W$ ) and to more precipitation than for CA.

The advective weather types from $\mathrm{W}, \mathrm{N}$ and $\mathrm{E}$ lead to rather low $T$ during the whole year, associated with a small diurnal cycle in $T$; RH shows a continuous decrease during the day that is superimposed on a diurnal cycle similar to that of aerosols. The advective type $\mathrm{W}$ is associated with a high 


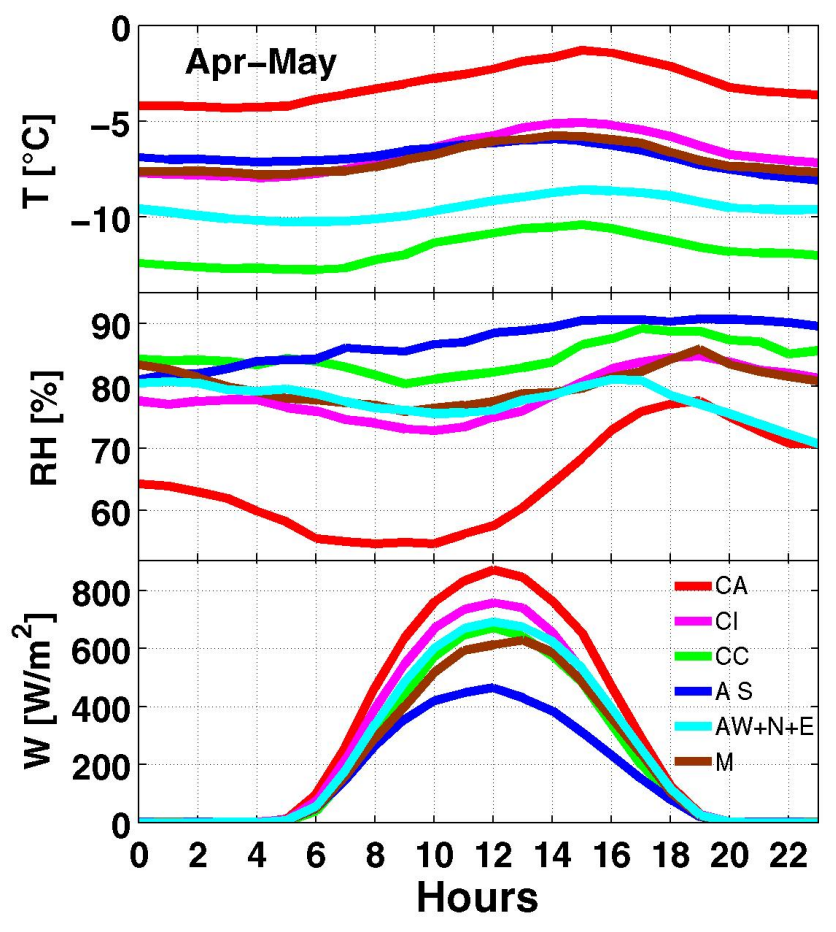

Fig. 4. Mean 1995-2008 diurnal cycles of the temperature, the relative humidity percentage $\mathrm{RH}$ and the global short wave radiation $W$ for the April-May period as a function of SYNALP weather types.

amount of precipitation, and type $\mathrm{E}$ with very low precipitation (not shown).

The AS weather type exhibits higher $T$, RH and precipitation, and lower $W$ than other advective situations during the whole year. It also leads to cloud coverage and a diurnal increase in RH associated with a continuous decrease in $T$ during the day that is superimposed onto a diurnal cycle in $T$ similar to that of aerosols (Fig. 4 and Table 3). The AS weather type usually leads to precipitation at the end of the day or the day after where the mean amount of precipitation the day after AS situations $(0.23 \mathrm{~mm})$ is greater than after all other weather situations (from 0.02 to $0.15 \mathrm{~mm}$ ).

The $\mathrm{M}$ weather type has low $W$ and intermediate $T$ and RH values during the whole year (Fig. 3), and middle to high precipitation.

\subsection{Median annual cycle of aerosol variables}

The 1995-2008 median annual cycles of dry $b_{\mathrm{abs}}, b_{\text {scat }}$ and $N$ are shown in Fig. 5a, the contributions of the different synoptic weather types are shown in colors; they are calculated accordingly to Eq. (1). Similar graphs with the relative contribution $\left(Y_{\text {SYNALP }(i)} / Y\right)$ of each SYNALP weather type to the total value $\mathrm{Y}$ of the aerosol variables are provided in Fig. 5b. Note that these numbers are influenced by both the absolute values of the aerosol variables and the frequency of occurrence of the weather type, as stated by Eq. (1).
The annual cycle is similar for all three aerosol variables presented in Fig. 5, with: (i) a maximum in July-August coincident with the maximum in $T$, (ii) a local maximum at the summer solstice, coincident with the maximum in $W$, as well as (iii) a second local maximum in April-May. The latter is principally due to the increase in $T$ and convective situations (CA and CI) leading to an increase of the aerosol concentration followed by a decrease of aerosol concentration due to wet removal by increased precipitation at the end of May and the beginning of June (Fig. 3). The summer is dominated by the influence of CA (subsidence) and CI situations, which together have a relative contribution of $75 \%, 72 \%$ and $66 \%$ of $b_{\text {scat }}, b_{\text {abs }}$, and $N$, respectively (see Fig. $5 \mathrm{~b}$ ). The CC type (lifting) has its greatest impact in the February-April period particularly on $N$. All three aerosol variables have their minimum in winter, when the greater influence of advective types on the scattering and absorption coefficients is related to a greater frequency of occurrence of these weather types (Fig. 2).

The annual cycle of $N$ (Fig. 5a) is less pronounced than those of $b_{\text {abs }}$ and $b_{\text {scat }}$ for all weather types, which is mainly due to the fact that $N$ is not only influenced by vertical transport but also by new particle formation and growth, which also proceeds in winter (Weingartner et al., 1999). The annual maximum of $N$ occurs at the summer solstice, which coincides with the maximum in $W$ and UV intensity, enhancing new particle formation. The annual cycle of $b_{\text {abs }}$ exhibits a lower local maximum in June than $\mathrm{N}$ and $b_{\text {scat }}$ due to its lower sensitivity to the growth of newly formed particles.

However, the annual cycles of $b_{\text {abs }}$ and particularly $N$ are quite different if only $\mathrm{M}, \mathrm{AW}+\mathrm{N}+\mathrm{E}$, AS and $\mathrm{CC}$ weather types are considered. In this case the maxima are found in April, while the summer concentration only presents a local maximum. Each weather type thus results in a different PBL influence at the JFJ (and consequently in different aerosol properties) depending on the periods of the year. The aerosol annual cycles allow periods of the year to be defined which show significant differences. First, the November-January period is characterized by low values of the aerosol variables and by a high frequency of occurrence of the AW+N+E weather type that particularly contributes to $b_{\text {abs }}$ and $b_{\text {scat }}$. Second, a rapid increase in aerosol variables occurs during February-March, associated with the greater influence of CC (lifting). Third, CA and CI weather types become predominant during April-May. Fourth, the June-August period is characterized by maximum values in all aerosol variables, due to the largest PBL influence. Finally the SeptemberOctober period is characterized by a rapid decrease in aerosol concentrations for all synoptic weather situations but particularly CA and CI. These five periods of the year have therefore been chosen to further investigate the diurnal cycles. 

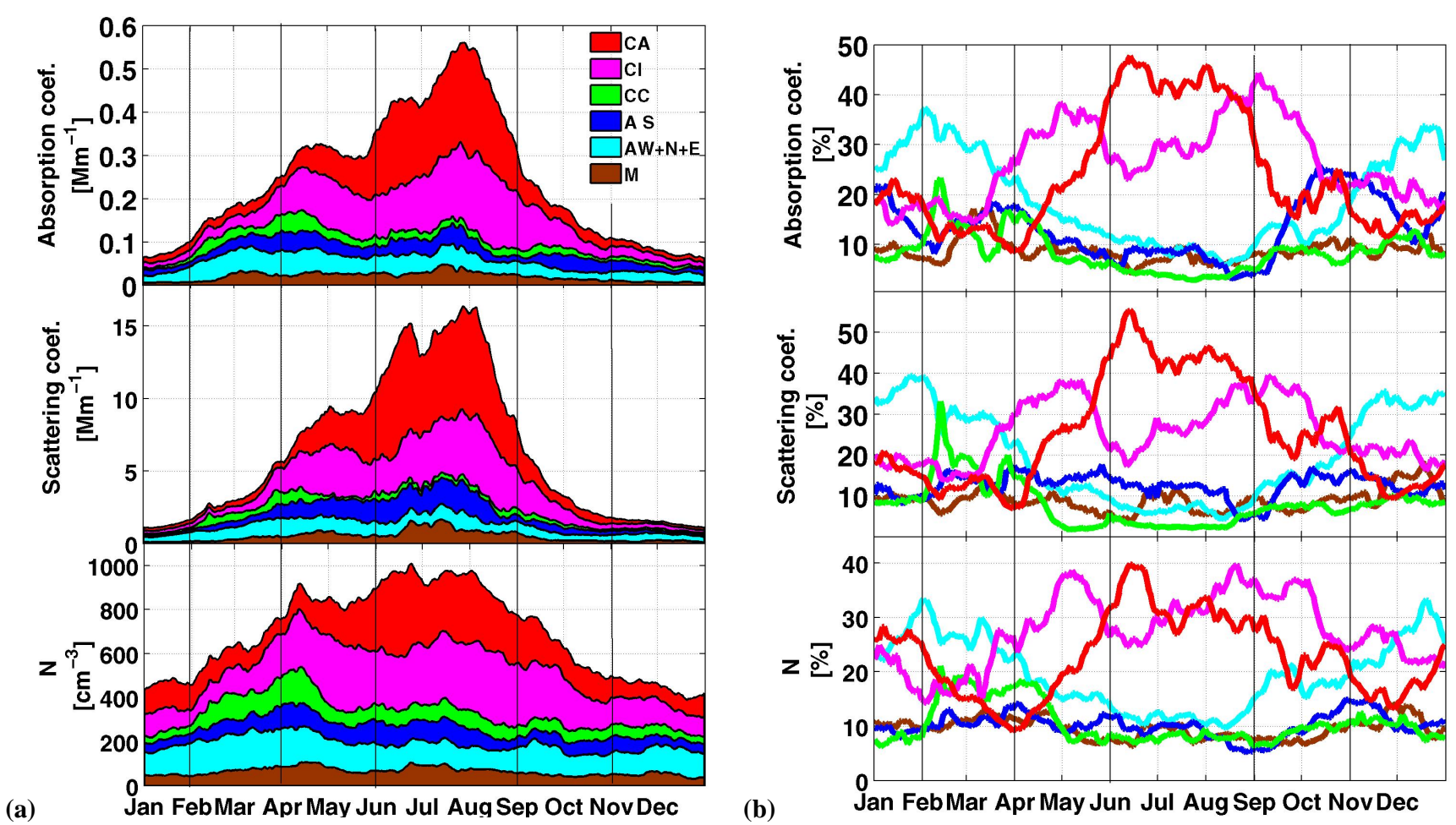

Fig. 5. Median 1995-2008 annual cycles of the absorption coefficient at $\lambda=880 \mathrm{~nm}$, the scattering coefficient at $\lambda=550 \mathrm{~nm}$ and the aerosol number concentration as a function of SYNALP weather types: (a) summed contributions of each weather type as a function of the measured variables during each weather type and its frequency of occurrence, (b) relative contributions of each weather type in $\%$.
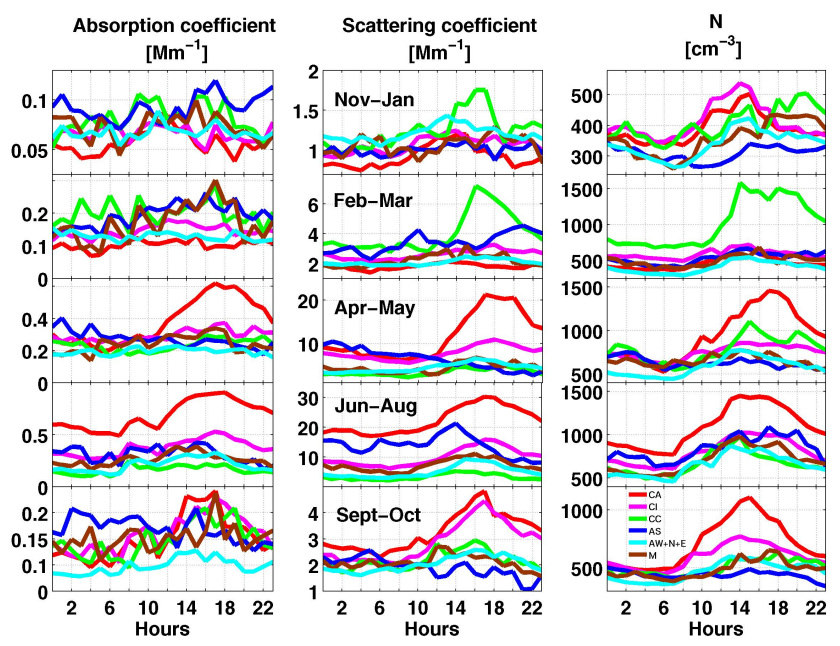

Fig. 6. Median 1995-2008 diurnal cycles of the absorption coefficient at $\lambda=880 \mathrm{~nm}$, the scattering coefficient at $\lambda=550 \mathrm{~nm}$ and the aerosol number concentration for 5 defined periods of the year (see middle graph for definition) as a function of SYNALP weather types.

\subsection{Median diurnal cycles in aerosol variables}

Diurnal cycles of $b_{\text {scat }}, b_{\text {abs }}$ and $N$ are presented in Fig. 6 for the five periods defined above. The $\mathrm{M}$ type is not represented in Fig. 6 since it does not correspond to a well defined meteorological situation. In addition, it occurs rarely and is never associated with high aerosol concentrations. However, its diurnal cycles are similar to those of advective situations from $\mathrm{W}, \mathrm{N}$ and $\mathrm{E}$ most of the time.

$N$ always exhibits the most pronounced diurnal cycles and $b_{\text {abs }}$ the least distinct diurnal cycles, especially in winter, due to their respective greatest and lowest sensitivities to the growth of newly formed particles (see Sect. 1). The JuneAugust period always leads to well defined diurnal cycles of $N$, with large amplitudes. The November-January and February-March periods display the weakest diurnal cycles of the year, with $b_{\text {abs }}$ exhibiting no diurnal cycles for most of the weather types. The maxima are usually found between 14:00 and 18:00, and the minima (if well defined) between 05:00 and 07:00. In summer, all weather types also present a local maximum in $b_{\text {abs }}$ between 08:00 and 10:00, similar to $\mathrm{NO}_{\mathrm{x}}$ (not shown) and $N$ that may be due to local contamination by diesel exhaust from a snowcat used for tourist purposes only in summer.

For most of the year, CA (subsidence) presents the largest diurnal cycles. In summer both the CA maxima and minima 


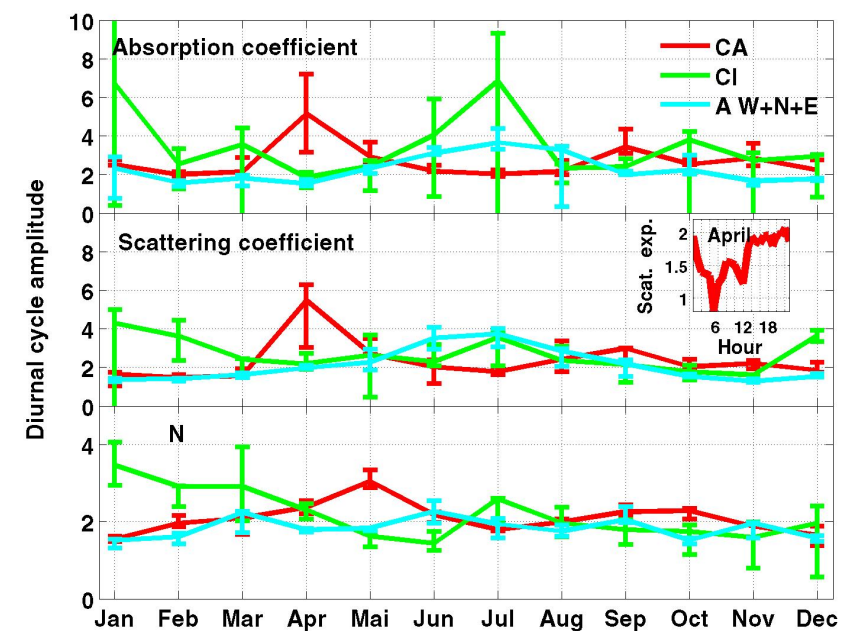

Fig. 7. Amplitude (max/min) of the diurnal cycles of $b_{\text {abs }}, b_{\text {scat }}$ and $N$ concentration for CA (subsidence), CC (lifting) and advective weather types from W, N and E. Figure 6b inset shows the April diurnal cycle of the scattering Ångström exponent at $550 \mathrm{~nm}$. Error bars correspond to non-parametric confidence limits.

are much higher than those of all the other weather types; the summer CA minima of $b_{\text {abs }}$ and $b_{\text {scat }}$ are even higher than the diurnal maxima for all other weather types and seasons. In September-October, $b_{\text {scat }}$ has a particularly large diurnal cycle compared to $b_{\mathrm{abs}}$ for the CA and CI weather types.

During CC situations, a larger diurnal cycle of $b_{\text {scat }}$ is observed during November-March periods with the highest daily maxima, whereas the $N$ diurnal cycle presents the same features only in February-March with high maxima and minima.

During April-October periods, the AS weather type presents a continuous decrease of all aerosol variables during the day, which is superimposed onto the usual diurnal cycle during summer. Such a continuous diurnal decrease is most probably due to aerosol wet removal on the Alpine windward side during AS situations.

To gain information on the PBL influence during the afternoon, the amplitude of the diurnal cycles - ratio between the maximum and the minimum values of the monthly median diurnal cycle - are plotted for $b_{\text {abs }}, b_{\text {scat }}$, and $N$ during $\mathrm{CA}, \mathrm{CC}$ and $\mathrm{AW}+\mathrm{N}+\mathrm{E}$ weather types (Fig. 7). Diurnal cycle amplitudes are neither plotted for the AS type since a continuous diurnal decrease is usually observed, nor for the CI type since their amplitudes remain rather constant between 1.4 and 2.7 throughout the year, nor for the $\mathrm{M}$ type that is similar to the AW+N+E type. The annual cycles of the diurnal amplitude are almost similar for the three described aerosol variables. For the CA type (subsidence), the diurnal cycles are significantly more pronounced in the spring (April-May) and in the autumn (September-October) and lower in summer. For the CC type (lifting), the diurnal cycles of $b_{\text {scat }}$ and $N$ are significantly more pronounced in January-March and

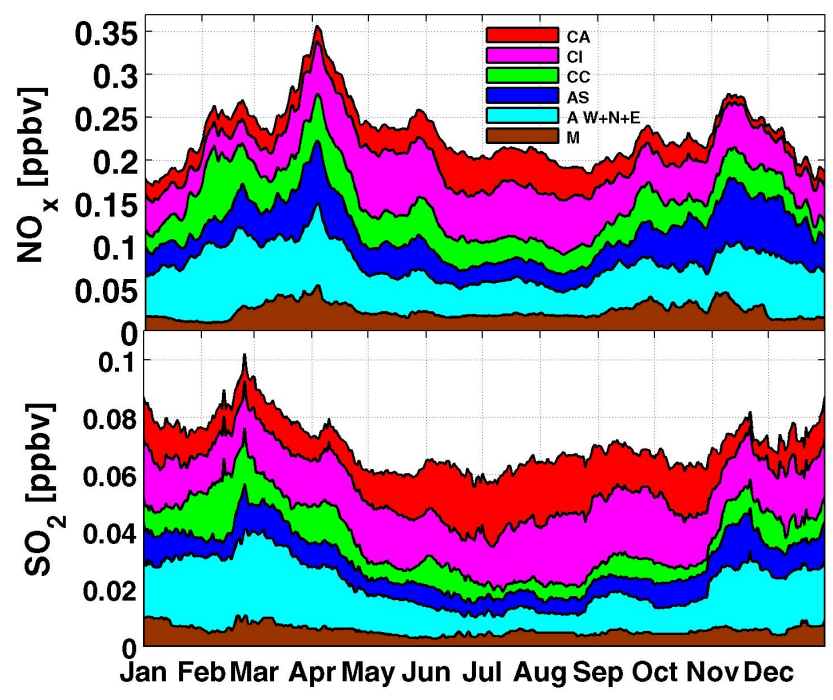

Fig. 8. Mean 1995-2008 annual cycles of $\mathrm{NO}_{\mathrm{x}}$ and $\mathrm{SO}_{2}$ concentrations as a function of SYNALP weather types.

in July. During advective situations from $\mathrm{W}, \mathrm{N}$ and $\mathrm{E}$, the diurnal cycles are most pronounced in summer for $b_{\mathrm{abs}}$ and $b_{\text {scat }}$, which is not observed for $N$. The inset in Fig. 7b shows the CA diurnal cycle of the scattering Ångström exponent in April, which is the only month showing a clear diurnal cycle with smaller values corresponding to larger particles in the morning, and larger values corresponding to smaller particles during the afternoon. The diurnal cycle of the aerosol size between the FT aged aerosol in the morning and the PBL aerosol in the afternoon is therefore only observed in April for the subsidence (CA) case. This means that for all other weather types and months, the scattering Ångström exponent cannot detect a diurnal evolution of the aerosol size distribution.

\section{Discussion}

\subsection{PBL influence at the JFJ}

Advective weather types are predominant from November to January with a $45 \%$ frequency (Fig. 2). During this period, $b_{\text {abs }}$ and $b_{\text {scat }}$ are effectively dominated by the contribution of advective weather types ( $>40 \%$, see Fig. 5), whereas $\mathrm{CA}$ and CI weather types also contribute substantially to $N$ $(50 \%)$. This difference is due to the sensitivity of $N$ to the growth of newly-formed particles at the JFJ and in the adjacent valleys (see the diurnal cycle of $N$ in winter, Fig. 6). The $\mathrm{SO}_{2}$ concentration, which enhances new particle formation, is at a maximum from November-April, whereas the $\mathrm{NO}_{\mathrm{x}}$ concentration, which enhances particle growth, is at a maximum in March-April and in November (Fig. 8). During winter, longer lifetimes and higher emissions (due to domestic heating, cold start engine conditions, etc) explain the 


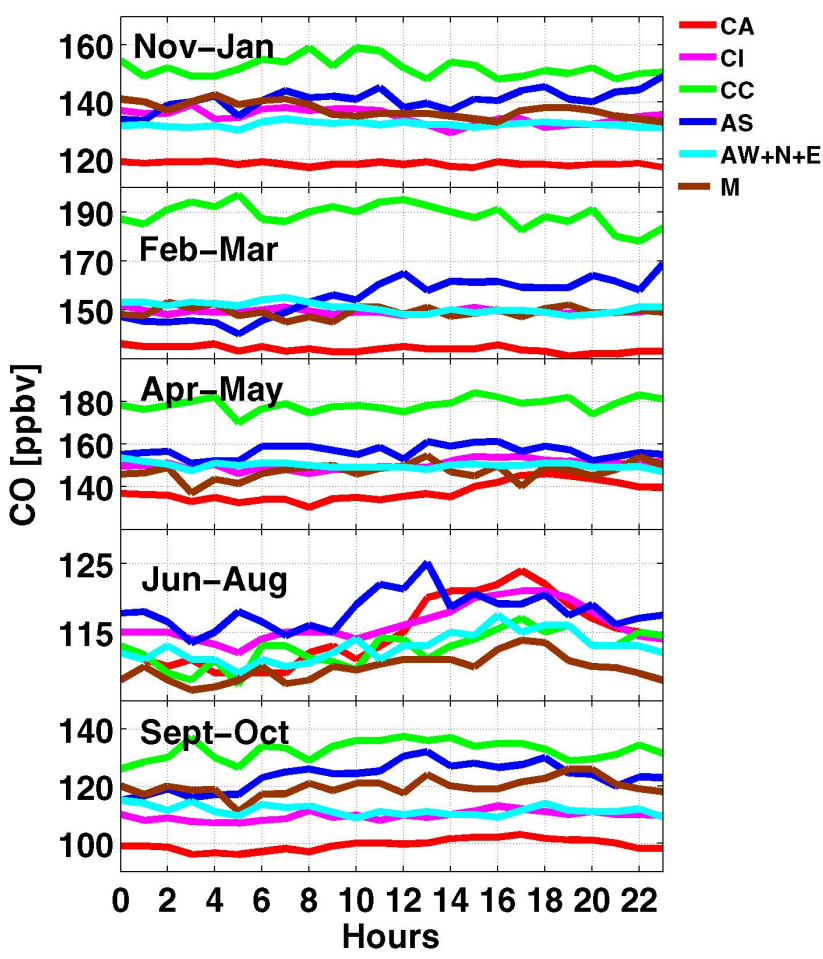

Fig. 9. Median 1995-2008 diurnal cycles of CO concentration for the 5 defined periods of the year as a function of SYNALP weather types.

higher concentrations of primary gas phase compounds measured in the FT at the JFJ (Balzani Lööv et al., 2008). The $\mathrm{CA}$ and $\mathrm{CI}$ weather types lead to high global radiation and the lowest cloud coverage, so that their contributions to new particle formation in winter are clearly visible in the annual cycle of $N$ (Fig. 5).

In February and March, $b_{\mathrm{abs}}, b_{\mathrm{scat}}$ and $N$ increase for all weather types, but particularly for lifting (CC) and advection from $\mathrm{W}, \mathrm{N}$ and $\mathrm{E}$. Lifting also shows particularly strong diurnal cycles in $N$ and $b_{\text {scat }}$. The absence of a diurnal cycle in $b_{\text {abs }}$ shows that the increase in $N$ and $b_{\text {scat }}$ during the afternoon is not due to aerosol from the Swiss plateau reaching the JFJ. The high $\mathrm{CO}$ concentration during the whole year (Fig. 9) indicates that the CC weather type allows PBL air masses to be transported to the JFJ altitude, but that aerosols are removed most of the time by wet deposition. The formation rate of new particles from gaseous precursors and their subsequent growth are generally enhanced by solar radiation, by lower temperature (due to higher supersaturations of the condensable gas phase species at colder temperatures; Clausius-Clapeyron equation), by high precursor concentrations and a low aerosol surface area concentration available as a condensational sink (i.e., a low concentration of accumulation mode particles). Clouds inhibit however new particle formation and growth processes and enhance loss processes of newly formed particles by scavenging (Boulon et

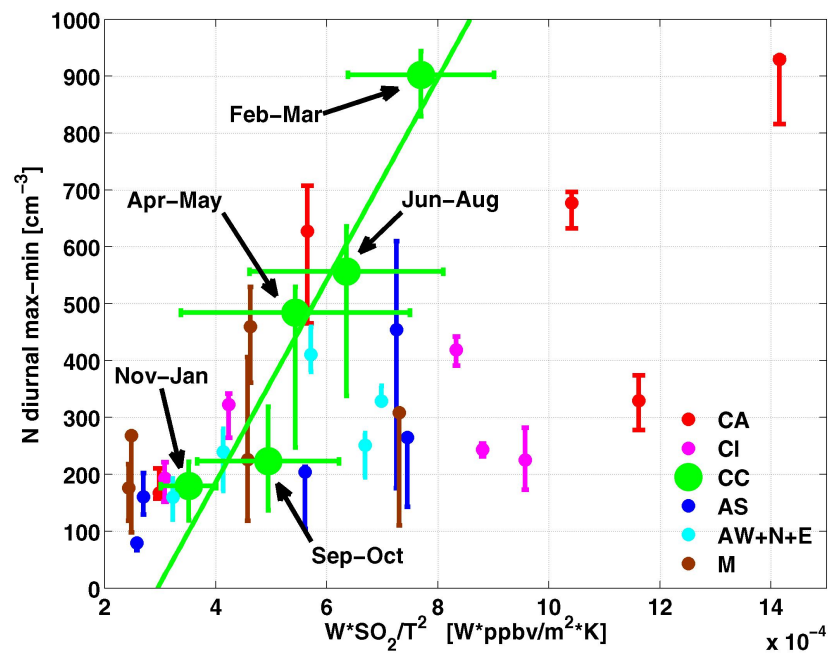

Fig. 10. Difference between the diurnal maximum and minimum in median $N$ values measured at the $\mathrm{JFJ}$ versus $W \cdot \mathrm{SO}_{2} / T^{2}$ measured at Payerne (Swiss plateau) for different SYNALP weather types, and periods of the year. The upper and lower confidence limits on the $y$-axis are calculated with a non-parametric estimator, where the $\mathrm{x}$-axis error bars are calculated with standard error propagation of the instrument uncertainties. The $\mathrm{x}$-axis error bars are plotted only for CC for the purpose of clarity.

al., 2010). In February and March, the high precursor concentration (Fig. 8) is associated with relatively high global radiation at the $\mathrm{JFJ}$ ( $W$ is higher during $\mathrm{CC}$ than during $\mathrm{M}$ and all advective weather types), low surface area concentrations and very low temperatures; all these parameters favor high rates of new particle formation and contribute to the diurnal cycle in $N$ and $b_{\text {scat. }}$. To model this dependence, the differences between the diurnal maximum and minimum in median $N$ values at the JFJ are plotted (Fig. 10) as a function of $W \cdot\left[\mathrm{SO}_{2}\right] / T^{2}$. The parameters $W$ (global short wave solar radiation), $\left[\mathrm{SO}_{2}\right]\left(\mathrm{SO}_{2}\right.$ concentration in ppbv), and $T$ (temperature in $\mathrm{K}$ ) are measured at Payerne which is considered to be representative of the Swiss plateau region. In this simplified model, $\left[\mathrm{SO}_{2}\right]$ is used as a proxy for all the precursors gases, while the square of the temperature was chosen to represent the temperature dependence of the Clausius-Clapeyron equation. Figure 10 shows that the high concentration of particles in February-March during CC can be simply explained by meteorological parameters and the precursor concentration over the Swiss plateau region. The contribution of new particle formation during $\mathrm{CC}$ is particularly visible in FebruaryMarch due to the very low aerosol number concentration during all other weather types. This correlation is worse for other weather types, due to the decoupling between the Swiss plateau region and the JFJ during the coldest months or to lower wet removal leading to a higher condensation sink. Weingartner et al. (1999) showed that the aerosol size distribution presents a high concentration of Aitken and nucleation mode particles in case of CC. However, considering all 
synoptic situations, new particle formation at the JFJ is at a maximum in late spring and early summer (Manninen et al., 2010; Boulon et al., 2010). The JFJ is further characterized by a high amount $(22.3 \%)$ of ion-mediated nucleation and a high growth rate $\left(\sim 5 \mathrm{~nm} \mathrm{~h}^{-1}\right.$ for particles in the range $d=1.3-20 \mathrm{~nm}$ (Boulon et al., 2010)).

In April and May, the CA and CI weather types become dominant, presenting the major contribution to all aerosol variables (Fig. 5). For subsidence (CA), large diurnal cycles are found for all aerosol variables and their amplitudes are at a maximum in April for $b_{\text {abs }}$ and $b_{\text {scat }}$, and in May for $N$ (Fig. 7). The CO concentration also shows a clear diurnal cycle during subsidence (Fig. 9). April is the only month presenting a clear diurnal cycle of the scattering Ångström exponent indicating a larger aerosol size (low scattering Ångström exponent) from 02:00 to $12: 00$ and a smaller aerosol size (high scattering Ångström exponent) from 14:00 to 24:00 (see insert in Fig. 7). The large diurnal cycles of aerosol variables, of CO concentration and of the Ångström exponent and the higher concentration of aerosols from more polluted air masses during the afternoon show that the influence of the PBL due to thermal convection occurs from April onward during the CA weather type. The minima of aerosol variables, CO concentration and of the Ångström exponent remain, however, similar to the values during winter and during April-May in case of all other synoptic weather types. These low aerosol and CO concentrations during the night associated with the presence of larger particles (Ångström exponent) prove that FT conditions prevail during the night for all weather types. This alternation of FT and PBL air masses leads to a maximum amplitude in diurnal cycles during the CA weather type. All other weather types exhibit a small diurnal cycle reflecting a very small and unsystematic influence of the PBL during the afternoon, while the AS weather type exhibits no diurnal cycle.

Aerosol variables are greatly enhanced in summer (JuneAugust) during subsidence (CA) even if the frequency of occurrence of the CA weather type is not really higher than during the rest of the year; the higher aerosol concentration is due to mountain venting induced by higher temperatures and allowing the export of PBL air to the FT, as was also observed by Henne et al. (2005b). The diurnal minima of all aerosol variables are much higher in summer for the CA weather type than for other weather types (see Fig. 6). Higher aerosol concentrations during the night are due to the remaining influence of residual layers under these meteorological (high $T$ ) and synoptic conditions. All other weather types also present pronounced diurnal cycles of aerosol variables, $\mathrm{RH}$ and $\mathrm{CO}$ concentration which implies that PBL air masses reach the JFJ during the afternoon due to high values of $T$ in summer, but that FT air masses prevail during the night. The high aerosol concentration during summer is lower at the beginning of June as a result of high precipitation, and lower in the second half of August due to both precipitation and lower $W$ during CA weather types.
Finally, the September-October period is characterized by a less sharp decrease in aerosol variables than in August with values similar to the February-March period, but with a larger diurnal cycle for all weather types except for CC (lifting). During CA and CI weather types, $b_{\text {scat }}$ and $N$ have a larger diurnal cycle than $b_{\text {abs }}$ due to higher global radiation and therefore enhanced new particle formation and growth. During autumn, thermally driven convection above the temperature inversion frequently brings high-alpine air masses to the JFJ (Lugauer et al., 2000).

The PBL influence at the JFJ as a function of the synoptic weather types is summarized in Fig. 11, which shows the diurnal maxima and minima of the median $b_{\text {abs }}$ and $N$. The $\mathrm{AW}+\mathrm{N}+\mathrm{E}$ weather type exhibits the lowest diurnal maximum in $b_{\text {abs }}$ and $N$ in winter, involving the smallest PBL influence and lowest concentration of newly formed particles. The PBL influence during the afternoon is shown by diurnal maxima in $b_{\text {abs }}$ and occurs from April-September during subsidence (CA) with a maximal PBL influence in July and August. The relatively high diurnal minima in $b_{\text {abs }}$ indicate the influence of residual layers at the JFJ during the night from June-August during subsidence (CA) and to a far lesser extent during the $\mathrm{CI}$ weather type. All other weather types (CC, $\mathrm{M}$ and all advective situations) present higher diurnal maxima in summer but the diurnal minima remain low, leading to a PBL influence during the afternoon but to FT conditions during the night. The growth of newly-formed particles is observed in January-April during lifting (CC) as can be seen in diurnal maxima and minima of $N$, although this high concentration of new particles can be explained by meteorological parameters and precursor concentrations over the Swiss plateau. Finally, new particle formation is also enhanced during subsidence (CA) due to higher global radiation, as can be seen by the higher diurnal maxima in $N$ during the whole year but particularly in September and October.

\subsection{Quantification of PBL air masses exported to the JFJ}

The export of PBL air masses to the JFJ can be quantified by the relative increase ( $r$ i) in the specific humidity and $\mathrm{CO}$ concentration (Prévôt et al., 2000; Henne et al., 2005b):

$r i=\frac{C_{\mathrm{JFJ}}(\text { afternoon })-C_{\mathrm{JFJ}}(\text { morning })}{\operatorname{average}\left(C_{\mathrm{PAY}}\right)-C_{\mathrm{JFJ}}(\text { morning })}$

where $C_{\mathrm{JFJ}}$ and $C_{\mathrm{PAY}}$ are the concentrations measured at the JFJ and in Payerne, respectively. For the morning and afternoon values, the averaged daily minimum (restricted to the morning between 04:00 and 12:00) and maximum (restricted to the afternoon between 12:00 and 23:00) were used, respectively. The average in Payerne was taken as the daily average between 09:00 and 20:00. The value of $r i$ for the specific humidity was calculated from measurements at Stabio (SwissMetNet station in Tessin, see Fig. 1) for AS situations, but $r i$ for the $\mathrm{CO}$ concentration is not reported since $\mathrm{CO}$ 

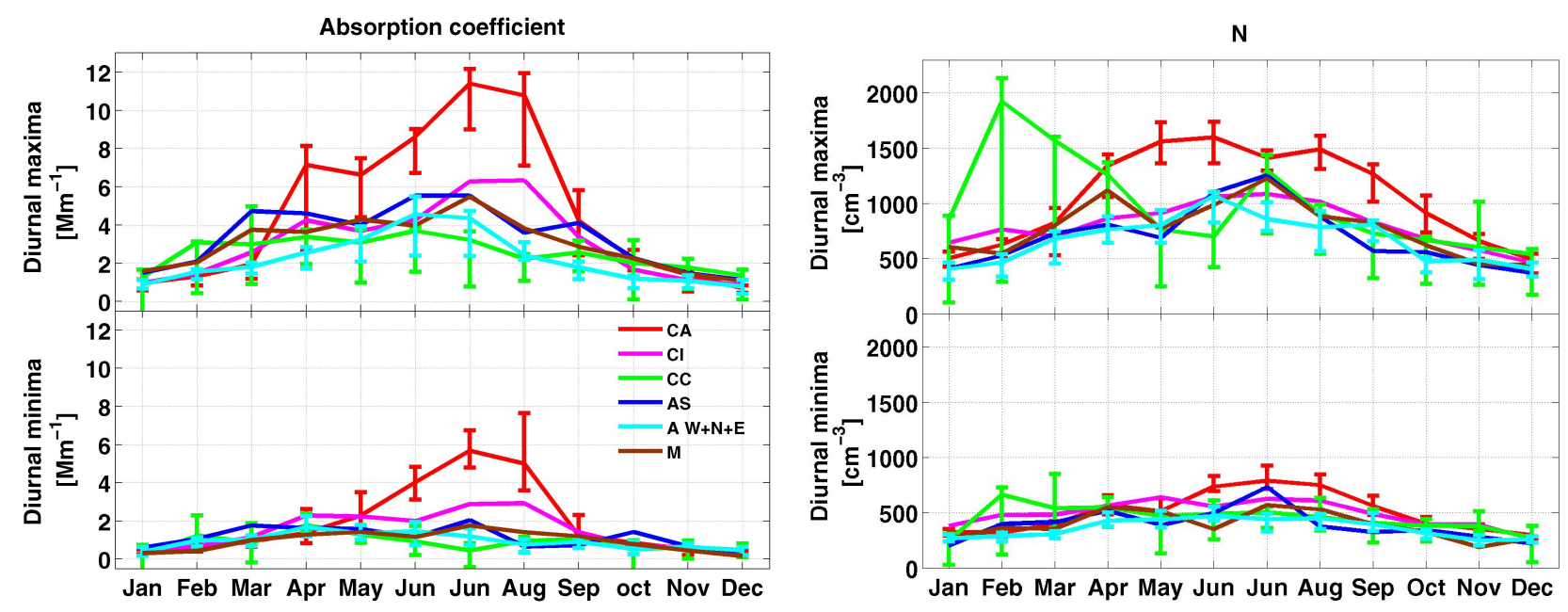

Fig. 11. Monthly diurnal maxima and minima of $b_{\mathrm{abs}}$ and $N$ as a function of SYNALP weather types. Error bars correspond to nonparametric confidence limits.

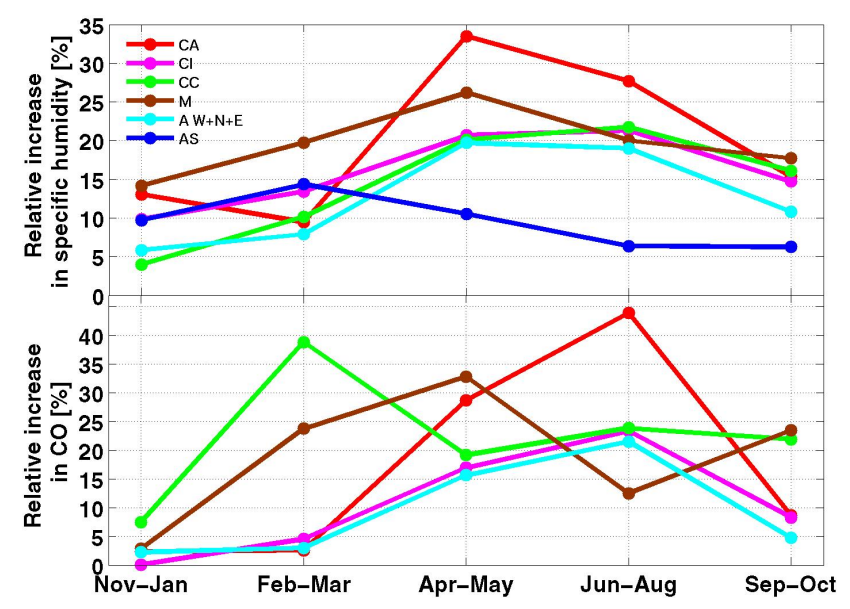

Fig. 12. Relative increase in the specific humidity and in CO concentration calculated from JFJ and Payerne data for all weather types and for the defined periods of the year. Data for the AS weather type was taken from the Stabio site, south of the Alps.

measurements south of the Alps are only reported for urban areas and are not representative of the boundary layer concentration. Days with a too high wind velocity $(>10 \mathrm{~m} / \mathrm{s})$ and precipitation $(>1 \mathrm{~mm} /$ day $)$ were excluded from this analysis (Henne et al., 2005b). When the vertical motion is zero then $r i=0 \%$, whereas similar concentrations measured at the JFJ and on the Swiss plateau would yield $r i=100 \%$. The maximum export of PBL air masses occurs during the CA weather type in the April-August period with respect to specific humidity and in June-August with respect to $\mathrm{CO}$ concentration, $r i$ reaching $35 \%$ and $45 \%$ respectively (see Fig. 12). For all other weather types, the mean ri during summer is about $20 \%$ for both the specific humidity and CO concentration. The lowest $r i$ values (5-10\%) are found in the November-
January period for the AW+N+E, CA and CI weather types. Since the CC weather type is often connected with precipitation, the relative increase in $\mathrm{CO}$ concentration probably leads to a better estimate of the export of PBL air masses to the JFJ than the specific humidity. The CO relative increase during lifting $(\mathrm{CC})$ is usually higher than for other weather types, with $25 \%$ from April-October, a minimum (7.5\%) in November-January and a maximum in February-March (40\%). The $\mathrm{M}$ weather type leads to high $r i$ for both the specific humidity and CO concentration for February-May. For the time with the lowest vertical transport (November to January and within this time period particularly for the weather types $\mathrm{AW}+\mathrm{N}+\mathrm{E}$ ), a maximum of $5-10 \%$ of PBL air masses are exported to the JFJ. During strong vertical transport weather types (CA in April-August, CC in FebruaryMarch), $r i$ always remains under $45 \%$ so that the most polluted air masses at the JFJ contain less than $50 \%$ of PBL air masses. In a study concerning two years of reactive nitrogen $\left(\mathrm{NO}_{y}\right)$ measurements (Zellweger et al., 2003), it was concluded that a $14-20 \%$ maximum contribution of PBL to FT air masses occurred during convective weather types, whereas a 12-year analysis of the specific humidity (Henne et al., 2004) concluded that a maximum of $30 \%$ of air masses between 2500 and $4000 \mathrm{~m}$ a.s.l. originated from the PBL.

A 10-year trend analysis of the aerosol optical properties showed that positive trends were found for the scattering, backscattering, and absorption coefficients and for the number concentration during the September-December period (Collaud Coen et al., 2007). This increase of the extensive aerosol properties during autumn was tentatively related either to modification of the PBL influence over large regions, or to long-range transport from areas with increasing air pollution. No significant trends were detected for summer when the JFJ is more strongly influenced by the injection of PBL air masses. An analysis of the trend of PBL influence 
at the JFJ is presently being performed and will help to explain the trends of the aerosol optical properties. This remains however a complex question that includes trends of the aerosol and meteorological parameters measured on the Swiss plateau and at the JFJ as well as trends in the diurnal cycles measured at the JFJ.

\section{Conclusions}

An analysis of a 14-year dataset (1995-2008) of meteorological and aerosol variables as well as gaseous compounds was performed for different synoptic weather types. Subsidence, lifting and advective weather types present three different seasonalities and lead to various PBL influences at the JFJ. The November-January period is characterized by very low aerosol concentrations and almost no diurnal cycle of the aerosol variables, demonstrating the negligible influence of the PBL for all synoptic weather types except for lifting (CC) which only occurs $6 \%$ of the time. In February and March, the lifting weather type makes a large contribution to the aerosol number concentration mainly through the growth of newly formed particles over the Swiss plateau. From March onwards, the subsidence (CA) and convective indifferent (CI) weather types gradually become the dominant weather types, and result in the JFJ being influenced by the PBL during the afternoon, while the night is predominantly influenced by the FT. During summer, the high temperatures lead to PBL influence by thermal convection for all weather types. For subsidence (CA) cases, air masses from residual layers continue to influence the JFJ during the night, leading to higher diurnal minima than for other weather types. Lower $W$ values during CA and generally higher precipitation in August lead to a rapid decrease of the aerosol variables after the temperature maxima at the end of July. A slower decrease is observed in September and October, however, with enhanced new particle formation for the subsidence and CI cases due to higher global radiation during these weather types. The JFJ is negligibly influenced by the PBL during winter for advective weather types. The largest PBL influence is found during summer for the convective anticyclonic weather type, when residual layers influence the JFJ during the night. An analysis of the relative increase of the specific humidity and $\mathrm{CO}$ concentration allows us to estimate that on average less than $45 \%$ of PBL air is found at the JFJ during all synoptic weather conditions.

Acknowledgements. We thank the International Foundation High Altitude Research Stations Jungfraujoch and Gornergrat (HFSJG), which made it possible to carry out the experiments at the High Altitude Research Station at the Jungfraujoch. We are grateful to the custodians at the Jungfraujoch for their inspection and maintenance of instrumentation. We gratefully acknowledge Ian Colbeck for lending the nephelometer during the first years of measurement at the Jungfraujoch. This work was supported by MeteoSwiss within the Swiss program of the Global Atmosphere
Watch (GAW) of the World Meteorological Organization as well as the EU FP6 project EUSAAR. The Swiss National Air Pollution Monitoring Network is run by Empa in joint collaboration with the Swiss Federal Office for the Environment.

Edited by: R. Krejci

\section{References}

Anderson, T. L. and Ogren, J. A.: Determining aerosol radiative properties using the TSI 3563 integrating nephelometer, Aerosol Sci. Technol., 29(1), 57-69, 1998.

Baltensperger, U., Gäggeler, H. W., Jost, D. T., Lugauer, M., Schwikowski, M., Weingartner, E., and Seibert, P.: Aerosol climatology at the high-alpine site Jungfraujoch, Switzerland, J. Geophys. Res., 102(D16), 19707-19715, 1997.

Balzani Lööv, J. M., Henne, S., Legreid, G., Staehelin, J., Reimann, S., Prévôt, A. S. H., Steinbacher, M., and Vollmer, M. K.: Estimation of background concentrations of trace gases at the Swiss Alpine site Jungfraujoch (3580 m asl), J. Geophys. Res., 113, D22305, doi:10.1029/2007JD009751, 2008.

Boulon, J., Sellegri, K., Venzac, H., Picard, D., Weingartner, E., Wehrle, G., Collaud Coen, M., Btikofer, R., Flückiger, E., Baltensperger, U., and Laj, P.: New particle formation and ultrafine charged aerosol climatology at a high altitude site in the Alps (Jungfraujoch, $3580 \mathrm{~m}$ a.s.l., Switzerland), Atmos. Chem. Phys., 10, 9333-9349, doi:10.5194/acp-10-9333-2010, 2010.

Chamaillard, K., Kleefeld, C., Jennings, S. G., Ceburnis, D., and O'Dowd, C. D.: Light scattering properties of sea-salt aerosol particles inferred from modeling studies and ground-based measurements, J. Quan. Spectrosc. Radiat. Transfer, 101, 498-511, 2006.

Collaud Coen, M., Weingartner, E., Nyeki, S., Cozic, J., Henning, S., Verheggen, B., Gehrig, R., and Baltensperger, U.: Long-term trend analysis of aerosol variables at the highalpine site Jungfraujoch, J. Geophys. Res., 112(D13), D13213, doi:10.1029/2006JD007995, 2007.

Collaud Coen, M., Weingartner, E., Apituley, A., Ceburnis, D., Fierz-Schmidhauser, R., Flentje, H., Henzing, J. S., Jennings, S. G., Moerman, M., Petzold, A., Schmid, O., and Baltensperger, U.: Minimizing light absorption measurement artifacts of the aethalometer: evaluation of five correction algorithms, Atmos. Meas. Tech., 3, 457-474, doi:10.5194/amt-3-457-2010, 2010.

Gibbons, R. D. and Coleman, D. E.: Statistical Methods for Detection and Quantification of Environmental Contamination, WileyInterscience, New York, USA, 242-244, 2001.

Henne, S., Furger, M., Nyeki, S., Steinbacher, M., Neininger, B., De Wekker, S. F. J., Dommen, J., Spichtinger, N., Stohl, A., and Prévôt, A. S. H.: Quantification of topographic venting of boundary layer air to the free troposphere, Atmos. Chem. Phys., 4, 497-509, doi:10.5194/acp-4-497-2004, 2004.

Henne, S., Dommen, J., Neininger, B., Reimann, S., Staehelin, J., and Prévôt, A. S. H.: Influence of mountain venting in the Alps on the ozone chemistry of the lower free troposphere and the European pollution export, J. Geophys. Res., 110, D22307, doi:10.1029/2005JD005936, 2005a.

Henne, S., Furger, M., and Prévôt, A. S.: Climatology of mountain venting-induced elevated moisture layers in the lee of the Alps, J. Appl. Meteorol., 44(5), 620-633, 2005b. 
Lugauer, M., Baltensperger, U., Furger, M., Gäggeler, H. W., Jost, D. T., Schwikowski, M., and Wanner, H.: Aerosol transport to the high Alpine sites Jungfraujoch (3454 m a.s.1.) and Colle Gnifetti (4452 m a.s.1.), Tellus B, 50(1), 76-92, 1998.

Lugauer, M., Baltensperger, U., Furger, M., Gäggeler, H. W., Jost, D. T., Nyeki, S., and Schwikowski, M.: Influences of vertical transport and scavenging on aerosol particle surface area and radon decay product concentrations at the Jungfraujoch (3454 m above sea level), J. Geophys. Res., 105(D15), 19869-19879, 2000.

Manninen, H. E., Nieminen, T., Asmi, E., Gagné, S., Häkkinen, S., Lehtipalo, K., Aalto, P., Vana, M., Mirme, A., Mirme, S., Hõrrak, U., Plass-Dülmer, C., Stange, G., Kiss, G., Hoffer, A., Töro, N., Moerman, M., Henzing, B., de Leeuw, G., Brinkenberg, M., G. N. Kouvarakis, A. Bougiatioti, N. Mihalopoulos, C. O’Dowd, D. Ceburnis, A. Arneth, Svenningsson, B., Swietlicki, E., Tarozzi, L., Decesari, S., Facchini, M. C., Birmili, W., Sonntag, A., Wiedensohler, A., Boulon, J., Sellegri, K., Laj, P., Gysel, M., Bukowiecki, N., Weingartner, E., Wehrle, G., Laaksonen, A., Hamed, A., Joutsensaari, J., Petäjä, T., Kerminen, V.-M., and Kulmala, M. : EUCAARI ion spectrometer measurements at 12 European sites - analysis of new particle formation events, Atmos. Chem. Phys., 10, 7907-7927, doi:10.5194/acp-10-79072010, 2010.

Nessler, R., Weingartner, E., and Baltensperger, U.: Adaptation of dry nephelometer measurements to ambient conditions at the Jungfraujoch, Environ. Sci. Technol., 39(7), 2219-2228, 2005.

Nyeki, S., Baltensperger, U., Colbeck, I., Jost, D. T., Weingartner, E., and Gäggeler, H. W.: The Jungfraujoch high-alpine research station $(3454 \mathrm{~m})$ as a background clean continental site for the measurement of aerosol parameters, J. Geophys. Res., 103(D6), 6097-6107, 1998a.

Nyeki, S., Li, F., Weingartner, E., Streit, N., Colbeck, I., Gäggeler, H. W., and Baltensperger, U.: The background aerosol size distribution in the free troposphere: An analysis of the annual cycle at a high-alpine site, J. Geophys. Res., 103(D24), 31749-31761, 1998b.

Nyeki, S., Kalberer, M., Colbeck, I., De Wekker, S., Furger, M., Gäggeler, H. W., Kossmann, M., Lugauer, M., Steyn, D., Weingartner, E., Wirth, M., and Baltensperger, U.: Convective boundary layer evolution to $4 \mathrm{~km}$ asl over high-Alpine terrain: Airborne lidar observations in the Alps, Geophys. Res. Lett., 27(5), 689692, 2000.

Prévôt, A. S. H, Dommen, J., and Bäumle, M.: Influence of road traffic on volatile organic compound concentrations in and above a deep Alpine valley, Atmos. Environ., 34(27), 4719-4726, 2000.

Schüepp, M.: Witterungsklimatologie, Klimatologie der Schweiz, Band III, Beilage zu den Annalen 1978, (available from MeteoSwiss, Zürich, Switzerland), 1979.
Schüepp, M. and Schirmer, H.: Climates of central Europe, in Climates of Central and Southern Europe, World Survey of Climatology, 6, 3-73, 1977.

Schwarb, M.: Witterunganalyse anhand der Alpenwetterstatistik mit Bezug auf den Niederschlag. Period 1945-1994, Berichte und Skripten Geogr. Institut ETH Zürich 58, 1996.

SMI (Swiss Meteorological Institut), Alpenwetterstatistik Witterungskalender. Beschreibung der einzelnen Parameter, (available from MeteoSwiss, Zürich), 1985.

Stefanicki, G., Talkner, P., and Weber, R. O.: Frequency changes of weather types in the Alpine region since 1945, Theor. Appl. Climatol., 60(1), 47-61, 1998.

Urfer, C.: Die Klimaregionen der Schweiz: Alpennordhang, Klimatol. Schweiz, 2, 2-247, 1979.

Wanner, H., Salvisberg, E., Rickli, R., and Schüepp, M.: 50 years of Alpine weather statistics (AWS), Meteorologische Zeitschrift, 7(3), 99-111, 1998.

Weatherhead, E. C., Reinsel, G. C., Tiao, G. C., Meng, X.-L., Choi, D., Cheang, W.-K., Keller, T., DeLuisi, J., Wuebbles, D. J., Kerr, J. B., Miller, A. J., Oltmans, S. J., and Frederick, J. E.: Factors affecting the detection of trends: Statistical considerations and applications to environmental data, J. Geophys. Res., 103, 17149-17161, 1998.

Weatherhead, E. C., Reinsel, G. C., Tiao, G. C., Jackman, C. H., Bishop, L., Hollandsworth, F. S. M., DeLuisi, J., Keller, T., Oltmans, S. J., Flemming, E. L., Wuebbles, D. J., Kerr, J. B., Miller, A. J., Herman, J., McPeters, R., Nagatani, R. M., and Frederick, J. E.: Detecting the recovery of total column ozone, J. Geophys. Res., 105, 22201-22210, 2000.

Weingartner, E., Nyeki, S., and Baltensperger, U.: Seasonal and diurnal variation of aerosol size distributions $(10<D<750 \mathrm{~nm})$ at a high-alpine site (Jungfraujoch $3580 \mathrm{~m}$ a.s.l.), J. Geophys. Res, 104(D21), 26809-26820, 1999.

Weingartner, E., Saathoff, H., Schnaiter, M., Streit, N., Bitnar, B., and Baltensperger, U.: Absorption of light by soot particles: determination of the absorption coefficient by means of aethalometers, J. Aerosol Sci., 34(10), 1445-1463, 2003.

Zellweger, C., Ammann, M., Buchmann, B., Hofer, P., Lugauer, M., Rüttimann, R., Streit, N., Weingartner, E., and Baltensperger, U.: Summertime $\mathrm{NO}_{\mathrm{y}}$ specification at the Jungfraujoch, $3580 \mathrm{~m}$ a.s.1., Switzerland, J. Geophys. Res., 105, 66556667, 2000.

Zellweger, C., Forrer, J., Hofer, P., Nyeki, S., Schwarzenbach, B., Weingartner, E., Ammann, M., and Baltensperger, U.: Partitioning of reactive nitrogen $\left(\mathrm{NO}_{y}\right)$ and dependence on meteorological conditions in the lower free troposphere, Atmos. Chem. Phys., 3, 779-796, doi:10.5194/acp-3-779-2003, 2003. 